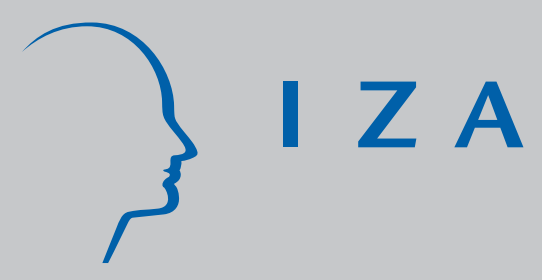

IZA DP No. 3907

Explaining How Delayed Motherhood Affects Fertility Dynamics in Europe

Massimiliano Bratti

Konstantinos Tatsiramos

December 2008 


\title{
Explaining How Delayed Motherhood Affects Fertility Dynamics in Europe
}

\author{
Massimiliano Bratti \\ University of Milan \\ and IZA \\ Konstantinos Tatsiramos \\ $I Z A$
}

\author{
Discussion Paper No. 3907 \\ December 2008
}

\author{
IZA \\ P.O. Box 7240 \\ 53072 Bonn \\ Germany \\ Phone: +49-228-3894-0 \\ Fax: +49-228-3894-180 \\ E-mail: iza@iza.org
}

Any opinions expressed here are those of the author(s) and not those of IZA. Research published in this series may include views on policy, but the institute itself takes no institutional policy positions.

The Institute for the Study of Labor (IZA) in Bonn is a local and virtual international research center and a place of communication between science, politics and business. IZA is an independent nonprofit organization supported by Deutsche Post World Net. The center is associated with the University of Bonn and offers a stimulating research environment through its international network, workshops and conferences, data service, project support, research visits and doctoral program. IZA engages in (i) original and internationally competitive research in all fields of labor economics, (ii) development of policy concepts, and (iii) dissemination of research results and concepts to the interested public.

IZA Discussion Papers often represent preliminary work and are circulated to encourage discussion. Citation of such a paper should account for its provisional character. A revised version may be available directly from the author. 


\section{ABSTRACT \\ Explaining How Delayed Motherhood Affects Fertility Dynamics in Europe}

This paper analyzes the effect of delayed motherhood on fertility dynamics for women living in several European countries, which differ in terms of their institutional environments. We show that the effect of delaying the first child on the transition to the second birth differs both among working and non-working women and across countries. For non-working women delayed motherhood leads to a postponement effect which is higher in countries where religion and social norms determine a relative larger stigma effect for giving birth late. For working women, delaying the first birth raises the likelihood of progressing to the second parity due to an income effect, which is larger in countries with high childcare provision and part-time employment opportunities. We show that the overall effect of delayed motherhood depends on these two opposite forces, which are determined by the institutional environment.

JEL Classification: $\quad \mathrm{C} 41, \mathrm{~J} 13$

Keywords: $\quad$ age, childbirth, duration, ECHP, fertility, postponement

Corresponding author:

Konstantinos Tatsiramos

IZA

P.O. Box 7240

53072 Bonn

Germany

E-mail: tatsiramos@iza.org

\footnotetext{
* This paper is partly based on work carried out by Massimiliano Bratti during his visits to the European Centre for Analysis in the Social Sciences (ECASS) at the Institute for Social and Economic Research (University of Essex) supported by the Access to Research Infrastructure action under the European Community's 'Improving Human Potential Programme', and IZA (Bonn), which are both acknowledged for financial assistance. The paper has benefited from comments received at seminars at IZA and Keele University, the BHPS conference in Colchester, the III Workshop on 'Economics of the Family' in Zaragoza, the ESPE conference in London and the EALE conference in Amsterdam. The usual disclaimers apply.
} 


\section{Introduction}

Two well known empirical facts regarding fertility in developed countries are the decline in Total Fertility Rates (TFRs), which are now below the so-called "replacement level" of 2.1 children per woman, and the increase in a woman's age at first birth. The negative correlation observed between a woman's age at first birth and total fertility suggests that delaying motherhood may be an important determinant of the fertility decline (postponement effect). Understanding these "tempo-quantum interactions" or tempo effects (Kohler et al., 2002) is important for policies aiming to address population aging and its negative economic consequences. Indeed, in the presence of a causal effect of age at first birth on subsequent fertility, policy makers may change fertility dynamics by affecting this age (Lutz and Skirbekk, 2005).

This paper contributes to the debate on delayed motherhood and fertility dynamics in three ways. First, we seek to provide micro-level evidence on the causal effect of age at first birth on the transition to the second parity. Estimating a multivariate discrete-time duration model, which accounts for correlated unobserved heterogeneity across parities, we are able to address the endogeneity of age at first birth. Endogeneity may arise because some unobserved variables, such as preferences towards having children or fecundability may simultaneously affect both fertility tempo and fertility quantum and generate a spurious correlation between the two. ${ }^{2}$ Second, unlike previous work mainly featuring individual country studies, we investigate the consequences of delayed motherhood on fertility in several European countries using highly standardized data from the European Community Household Panel (ECHP). This enables us to analyze the

\footnotetext{
${ }^{2}$ The focus on the first two parities is motivated by the fact that despite the declining trend in TFRs, survey data usually show that the modal desired number of children per woman is still two, and that many women fail even this relatively low fertility target (Bongaarts, 2001).
} 
pace of tempo effects separately in each country and to relate potential differences in these effects to countries' specific institutional features. Third, we consider the interplay between female labor force participation and fertility decisions and the extent to which it varies across institutional environments. ${ }^{3}$ That is, we examine whether female labor force participation always leads to lower fertility through a postponement effect, or if in the presence of specific institutions, delayed motherhood may represent a way to reconcile children and work, and have a positive impact on fertility of working women (catch-up effect). ${ }^{4}$ The distinction between working and non-working women also helps us to reconcile the contrasting evidence on postponement effects coming from previous studies. $^{5}$

Our paper suggests that tempo effects are the result of two opposite forces produced by delayed motherhood. On the one hand, as already stressed by the literature, delayed motherhood is less costly for a woman's working career (career-planning motive), raises life-time income and may have a positive income effect on fertility. On the other hand, there are both social and biological forces which lower the fertility of late mothers. Our empirical analysis shows that cross-country differences in the pattern of tempo effects are likely to depend on the differences in the income effect produced by a delayed motherhood. In countries with high childcare provision and part-time employment opportunities, such as Denmark and France, the income effect produced is large, leading to an overall increase of total fertility (catch-up effect). In contrast, late

\footnotetext{
${ }^{3}$ As it is well known, female life-cycle labor force participation and fertility decisions are closely related (see for instance, Moffit, 1984; Hotz and Miller, 1988; Francesconi, 2002).

${ }^{4}$ The centrality of labor market and child care institutions in shaping both the direct and indirect costs of childbearing and the correlation between maternal work and fertility has been recently stressed by Ahn and Mira (2002), among others. Bettio and Villa (1998) state that with the extremely low levels of fertility currently prevailing in Europe "the burden of making motherhood more compatible with working life falls mainly on the timing of births" (p. 166).

${ }^{5}$ For instance, Heckman et al. (1985) show the existence of a catch-up effect in Sweden, while Kohler et al. (2002) find a strong postponement effect in Southern European countries.
} 
motherhood decreases total fertility in Mediterranean countries (postponement effect) since the limited availability of childcare and the lack of flexible labor market arrangements raise the cost of childbearing, and the income effects are not large enough to counterbalance the strong cultural influences that make a late childbearing socially undesirable.

The structure of the paper is as follows. The following section introduces a simple analytical framework to investigate the tempo effects. Section 3 introduces the ECHP data and reports some sample descriptive statistics, while Section 4 describes the multivariate discrete-time duration model used in the empirical analysis. In Section 5 we report and discuss our main findings concerning the effect of the age at first birth on the timing of the second childbirth. The last section concludes.

\section{An analytical framework for tempo effects}

In this section we set a simple analytical framework, which helps us to motivate our empirical strategy and to interpret the results. We distinguish the overall effect of delayed motherhood (tempo effects) into three causal pathways. The first two (the biological effect and the stigma effect) operate on all women irrespective of labor force participation, while the third one (the income effect) operates only on women who participate in the labor market. Each of these pathways is likely to produce either a postponement effect, i.e. a negative effect on the hazard of progressing to the following parities, or a catch-up effect, i.e. a positive effect on higher parity progression. In the following, we discuss each of these channels and the extent to which they might differ across countries.

The biological effect. The first mechanism through which women who delay the birth of their first child might be slower in achieving the following parities or have a 
lower total fertility is that fecundity declines with age. Several studies have shown that women who delay childbearing after the age of 30 are at greater risk of remaining childless due to declining fecundity (see for instance, Howe et al., 1985; van NoordZaadstra et al., 1991). This causal pathway from age at first birth to fertility produces a postponement effect. Given that the technology addressing infertility problems is likely to be equally available in all developed countries, this effect should operate in the same way in all countries in our study.

The stigma effect. In traditional societies in which mothers are the primer provider of childcare, there might be a stigma attached to late childbearing. Hence, women who have their first child late may refrain from having additional children, even if they could. The importance of social norms and religion in shaping fertility decisions is stressed, for instance, by Heckert and Teachman (1985), who show that in the U.S., in a context of pro-natalistic norms such as Catholic ones, greater religiosity increases the pace of second births. Similarly, Adserà (2006) finds that practicing Catholic women in Spain are faster in achieving the second and following parities. This causal pathway from age at first birth to fertility produces a postponement effect. However, unlike the biological effect, the stigma effect is likely to be country-specific given the different cultural environments prevailing in European countries. For instance, it is expected to be larger in countries such as Ireland, Italy, Portugal and Spain, where religious participation is higher (see Table 1).

The income effect. Dynamic models of fertility have shown that there are two main motives for delaying fertility: "consumption smoothing" and "career planning" (see, for instance, Cigno and Ermisch, 1989; Blackburn et al., 1993; Walker, 1995; Gustafsson, 
2001). The consumption smoothing argument posits that, in the presence of capital market imperfections, women have children when their incomes are high enough to bear the costs of childrearing and to smooth consumption intertemporally. The career planning motive posits that working women give birth when it penalizes their careers less. Given that the age-profile of labor income is positive and steeper at younger ages, the first childbirth often occurs when working women have already accumulated a substantial amount of work experience. Therefore, delaying motherhood may produce an increase in women's wages and lifetime earnings and raise their demand for children (Ahn and Mira, 2002; Apps and Rees, 2004; Martínez and Iza, 2004). ${ }^{6}$

However, the magnitude of this positive income effect of delaying motherhood on higher parity progression (catch-up effect) is likely to vary across countries depending on the price of children. In countries in which provision of both low-cost external childcare and part-time opportunities are high, the opportunity cost of childbearing and the price of children are relatively low, so the income effect may be high. In these countries, mothers in full-time employment can use external childcare without reducing their working hours, or they can temporarily switch to part-time employment around childbirth, without penalizing their careers. In contrast, in countries with low provision of public childcare and part-time employment opportunities, the price of childbearing for working women is high, and an increase in lifetime resources due to delayed motherhood is unlikely to have strong income effects on fertility. In these countries working is incompatible with having many children (Del Boca and Sauer, 2008). Table 1 shows that countries such as

\footnotetext{
${ }^{6}$ Evidence that late motherhood is positively associated with mothers' wages can be found in Amuedo-Dorantes and Kimmel (2005) and Miller (2008), while Davies and Pierre (2005) use ECHP data to show that mothers under 24 are more likely to suffer from a family wage gap than older mothers. Del Bono et al. (2008) show that an unexpected career interruption has a sizeable negative effect on women's fertility. This effect could be explained by a reduction in expected life-time earnings due to the destruction of firm-specific human capital.
} 
Denmark, Belgium and France provide both high coverage of childcare and part-time employment opportunities; while the Mediterranean countries (Italy, Greece, Portugal and Spain) are characterized by both low childcare coverage and a low share of part-time employment.

The discussion above suggests some guidelines for our empirical analysis. First, the average effect of delaying the first birth on progression to the second parity is likely to differ according to a woman's employment status. Hence, interaction effects between age at first birth and labor force status should be considered. Second, the sign and the overall magnitude of tempo effects are likely to depend on the specific institutional and cultural features of each country. Hence, separate analyses for each country are preferred to a pooled country analysis.

\section{Data}

The analysis is based on individual data from the European Community Household Panel (1994-2001). The ECHP is a survey based on a standardized questionnaire that involves annual interviewing of a representative panel of households and individuals in each country, covering a wide range of topics including demographics, employment characteristics, education, etc. In the first wave, a sample of some 60,500 nationally representative households from 12 Member States - approximately 130,000 adults aged 16 and over - were interviewed. The features that make the ECHP relevant for this study are the standardized methodology and procedures yielding comparable information across countries and the longitudinal design in which information on the same set of households and persons is gathered.

In this study we focus on 10 countries (Belgium, Denmark, France, Germany, 
Greece, Ireland, Italy, Portugal, Spain and the United Kingdom), which have participated since the beginning of the survey, excluding Luxembourg because of its small sample size and the Netherlands due to missing relevant information. The sample consists of all women between 28 and 37 years old at the first observed wave (1994). We construct the age of the mother at each birth using the age of the children in the household. We define the duration until first birth as the time elapsed since age 17 until the age at the birth of the first child. Women who never give birth are considered right-censored observations. For those who give birth to the first child, we can construct the duration to the second childbirth. $^{7}$

Table 1 shows the share of women above 35 who are childless at the last observed wave (2001). The highest shares are observed for Italy (20.3\%), Germany (18.5\%) and Spain (18.1\%). On average, the share of childless women seems to be slightly higher in Southern European (16.5\%) compared to other European countries (15.3\%). Table 1 also shows that countries with a high share of childless women have a low share of women with more than one child. For instance, Italy, which has the highest share of women without children, also has the lowest share of women with more than one child (41\%). The last column depicts the mean age at first birth for women above 35 at the last observed wave, who are close to completing their fecund life-span. Greece and Portugal exhibit the lowest mean age (24.1 and 23.9, respectively).

\footnotetext{
${ }^{7}$ The sample selection on women's age is made mainly for two reasons. First, we want women to be close to the end of their fecund time-span at the last observed wave (Heckman et al., 1985). Second, we want to select women who are not too old to avoid the risk that they will appear childless because their children have already left the parental home. Table A1 in the Appendix provides summary statistics of the sample.
} 


\section{The econometric model}

Several studies have found a negative correlation between women's age at first birth and fertility (Morgan and Rindfuss, 1999, Kohler et al 2002 among others). However, these studies do not address the issue of potential endogeneity of the first birth with progression to higher parities. Endogeneity may arise because some unobserved variables, such as preferences towards children or fecundability may simultaneously affect both fertility tempo and fertility quantum and generate a spurious correlation between the two. Without taking into account these unobserved effects it is not possible to distinguish a true causal effect from a simple spurious correlation. To the best of our knowledge, only a few studies have tried to tackle the issue of endogeneity. Heckman et al. (1985) studied tempo effects in Sweden using a multivariate transition model and found a catch-up effect. Kohler et al. (2001) addressed the endogeneity issue using a sibling-estimator and found a postponement effect for Denmark. We contribute to these single country studies by seeking to estimate the causal effect of fertility tempo in several countries, which strongly differ in terms of both culture and institutions.

The statistical analysis is based on a multivariate discrete-time duration model, in which both the transition to the first birth and the transition to the second birth, conditional on the age at first birth, are modeled. Following Heckman et al. (1985) we distinguish the true causal effect of the age at first birth on the transition to the second parity from the spurious correlation due to individual unobserved heterogeneity, that is, to unobserved characteristics which simultaneously determine both the age at first birth and 
the occurrence of a second birth. ${ }^{8}$

The hazard function, which is defined as the probability that a spell is completed at time $t$ given that it has not been completed before $t$, as a function of $t$, is the basic building block of the discrete-time duration model. In the present context, we define the duration until the first birth $\left(T_{1}\right)$ as the time in years elapsed since age 17 and the duration until the second birth $\left(T_{2}\right)$ as the elapsed time in years since the time of the first birth.

The hazard function for an individual $i$ in state $j=1,2$, which indicates the two transition states, is defined as

$$
\lambda_{j i}\left(t_{j i} \mid y_{j i}\right)=P\left[T_{j i}=t_{j i} \mid T_{j i} \geq t_{j i}, y_{j i}\right]=F\left(y_{j i}\right)
$$

where $F(\cdot)$ denotes the logistic cumulative distribution function. For the transition to the first birth, where $j=1$, the index $y_{j}$ (abstracting from the subscript $i$ ) is defined as

$$
y_{1}=\beta_{01}+\beta_{11} \mathbf{X}_{1}+\sum_{k=1}^{K} \beta_{21} I_{k}\left(t_{1}\right)+\varepsilon_{1}
$$

where the vector $\mathbf{X}_{1}$ includes both time-invariant and time-variant individual characteristics. The effect of duration dependence is modeled by using the yearly time dummies $I_{k}\left(t_{1}\right)$, where $t_{1}$ denotes realizations of the stochastic duration of the spell since age 17 until the first birth, and $k=(1, \ldots, K)$ refers to the year intervals since age 17 .

Similarly for the transition to the second birth, where $j=2$, the index $y_{j}$ is defined as

\footnotetext{
${ }^{8}$ The use of bivariate duration models is common in the analysis of labor market dynamics (see Lancaster, 1990 and van den Berg, 2001 for an overview), but it has also been used extensively in health economics in the analysis of the use of alcohol and tobacco (van Ours, 2004) or drugs (van Ours, 2003).
} 


$$
y_{2}=\beta_{02}+\beta_{12} \mathbf{X}_{2}+\beta_{22} T_{1}+\sum_{k=1}^{K} \beta_{22} I_{k}\left(t_{2}\right)+\varepsilon_{2},
$$

where $t_{2}$ denotes realizations of the stochastic duration of the spell since the first birth. In both equations (2) and (3), $\varepsilon$ denotes the unobserved random factors that affect the transitions to the first and to the second birth, respectively. The specification in (3) includes the duration until the first birth, denoted as $T_{1}$, where the coefficient $\beta_{22}$ on this variable identifies the true tempo effects. In particular, $\beta_{22}>0$ is consistent with catch-up effects while $\beta_{22}<0$ with postponement effects. The effect of duration dependence is modeled by using the yearly time dummies $I_{k}\left(t_{2}\right)$, where $t_{2}$ denotes realizations of the stochastic duration of the spell since the year of the first birth until the second birth, and $k=(1, \ldots, K)$ refers to the year intervals since the first birth.

Using the hazard functions in equation (1), the contribution to the likelihood can be defined for each individual. Let $T_{j}^{0}$ denote the observed censored duration for $j=1,2$ so that $T_{j}^{0}=T_{j}$ if $T_{j}<C_{j}$ and $T_{j}^{0}=C_{j}$ otherwise, $C_{j}$ is the censored observed duration. The contribution of a completed spell is given by the conditional density function

$$
f_{j}\left(t_{j} \mid \cdot\right)=\lambda_{j}\left(t_{j} \mid \cdot\right) \prod_{t_{j}=1}^{T_{j}^{0}-1}\left(1-\lambda_{j}\left(t_{j} \mid \cdot\right)\right)
$$

while the contribution of a censored spell is given by the conditional survival function

$$
S_{j}\left(t_{j} \mid \cdot\right)=\prod_{t_{j}=1}^{T_{j}^{0}}\left(1-\lambda_{j}\left(t_{j} \mid \cdot\right)\right)
$$

The total sample likelihood is given by the product of the individual likelihoods

$$
L\left(\theta, \varepsilon_{1}, \varepsilon_{2}\right)=\prod_{i=1}^{N} L_{1}\left(\theta_{1}\right) L_{2}^{c_{1}}\left(\theta_{2}\right) d G\left(\varepsilon_{1}, \varepsilon_{2}\right),
$$


where $L_{j}(\theta)=\left[f_{j}\left(t_{j} \mid \cdot\right)\right]^{c_{j}}\left[S_{j}\left(t_{j} \mid \cdot\right)\right]^{1-c_{j}}, \theta_{1}$ and $\theta_{2}$ are the parameters to be estimated, $N$ is the number of individual spells and $c_{j}$ are dummies that take the value one for a completed spell $\left(T_{j}<C_{j}\right)$ and zero for a censored spell $\left(T_{j}=C_{j}\right)$. Note that the spells for the second birth contribute to the likelihood when the spell for the first birth is not censored (i.e. $\left.c_{1}=1\right)$.

The unobserved heterogeneity distribution $G\left(\varepsilon_{1}, \varepsilon_{2}\right)$ is defined flexibly as a discrete distribution with support points denoted by $\varepsilon_{j p}$ and the corresponding probability mass given by $\operatorname{Pr}\left(\varepsilon_{j}=\varepsilon_{j p}\right)=\pi_{p}$, where $p=1, . ., P$ denotes the support points. This approach in modeling unobserved heterogeneity is used frequently in labor economics and originates from Heckman and Singer (1984). Each unobserved factor is assumed to be time-invariant and individual specific, and it is allowed to be correlated across transitions. With two mass points for each unobserved component (random effects), there may be four types of individuals that are different in terms of their inclination to reach the first and the second parity because they have, for instance, a different desired fertility

$$
\begin{aligned}
& \operatorname{Pr}\left(\varepsilon_{1}=\varepsilon_{11}, \varepsilon_{2}=\varepsilon_{21}\right)=\pi_{1}, \quad \operatorname{Pr}\left(\varepsilon_{1}=\varepsilon_{11}, \varepsilon_{2}=\varepsilon_{22}\right)=\pi_{2}, \\
& \operatorname{Pr}\left(\varepsilon_{1}=\varepsilon_{12}, \varepsilon_{2}=\varepsilon_{21}\right)=\pi_{3}, \quad \operatorname{Pr}\left(\varepsilon_{1}=\varepsilon_{12}, \varepsilon_{2}=\varepsilon_{22}\right)=\pi_{4},
\end{aligned}
$$

where $0 \leq \pi_{p} \leq 1, \quad \sum_{p=1}^{4} \pi_{p}=1 \quad$ with $\quad p=1, . .4$ and $\pi_{p}=\exp \left(\alpha_{p}\right) / \sum_{p=1}^{4} \exp \left(\alpha_{p}\right) \quad$ with normalization $\alpha_{4}=0$ to have a multinomial logit specification. ${ }^{9}$

The sample log-likelihood can be written as follows

\footnotetext{
${ }^{9}$ We have also considered three mass points in the empirical analysis, but either they did not improve the estimation results, or they could not be identified.
} 


$$
\log L=\sum_{p=1}^{4} \pi_{p} \log L_{p},
$$

where $\log L_{p}$ is defined as in (6) for a specific mass point $p$. In the presence of a constant term in the vector of the observed covariates, we normalize the first mass point $\varepsilon_{j 1}$ to zero, so that the estimated coefficient for the second mass point denotes the deviation from the constant term.

Identification of multivariate discrete-time duration models is discussed by Cameron and Heckman (1998). They show that identification is enhanced if the index varies with duration without the need of exclusion restrictions. This condition is satisfied

in the presence of time variant regressors in $\mathbf{X}_{1}$ and $\mathbf{X}_{2} \cdot{ }^{10}$ It is important to note that the data do not provide observations on drawing from the mixing distribution of unobserved characteristics $G$ in (6). The information on $G$ comes from the observed interaction between duration and the observed individual characteristics. By allowing for the unobserved factors to be correlated across the two durations, we control for potential selectivity which might confound the effect of the age at first birth on the transition to the second.

\section{Results}

We estimate the model for the transitions to the first and the second childbirth under two different assumptions. The first, which is the benchmark case, uses the "piecemeal approach" (Heckman et al, 1985), assuming that the transitions to the first and the second parity are independent. The second allows for dependence across transitions by way of

\footnotetext{
${ }^{10}$ Even with a constant index, their Theorem 4 shows that the model is identified if attention is restricted to finite mixture distributions of the type defined above.
} 
correlated unobserved heterogeneity, as discussed in the previous section.

The specification for the transition to the first birth includes both time-variant and time-invariant regressors. The time-variant variables are a dummy for being engaged in full-time education, marital status (married and divorced) and a quadratic for years since first job. The time invariant variables include the highest educational level achieved and a dummy for having been employed. The highest educational level achieved is classified in three levels according to the International Standard Classification of Education (ISCED): "higher" for recognized higher education, "medium" for second stage of secondary education and "low" for lower than secondary education. For those women who have not yet completed education, this variable captures the effect of the expected level of education. We prefer the time-invariant information on ever being employed to timevariant current employment status mainly for two reasons. First, the information on individual labor market status is only observed for 1994-2001, so it is not available for the whole period from age 17 to the time of first birth for all women. ${ }^{11}$ Second, the variable ever employed is less likely to be endogenous with respect to the timing of fertility compared to current labor force status, since in developed countries, where age at first birth is relatively high, being employed at least once in the life-time is less likely to be hindered by giving birth to the first child. Finally, the years since first job proxy for potential experience for employed women.

The transition to the second birth includes the same controls as those for the first childbirth, except for the student status dummy. The student indicator, which is a time variant, is only included in the transition to the first birth, as student status is generally

\footnotetext{
${ }^{11}$ Estimating a specification including the current labor force status would require focusing only on the period 19942001 and on the women aged 17 in 1994 who experienced two childbirths in the same period, which would considerably restrict the sample size. For the same reason, we do not include partners' characteristics.
} 
not compatible with childrearing and is aimed to capture a purely mechanical postponement effect. ${ }^{12}$ In addition, the transition to second birth includes the age at which a woman first gave birth, which captures the tempo effects, and a dummy variable for the first child being male to account for potential gender bias towards either sons or daughters. Finally, we include year dummies in both equations to capture time-varying policies or macro-economic factors which might affect fertility decisions, and duration dependence dummies.

\subsection{Transition to the first birth}

Table 2 shows the estimation results from the benchmark case based on the assumption of independent transitions. ${ }^{13}$ Starting with the transition to the first birth, characteristics which are generally associated with a delay of the first childbirth are: being a student; having completed higher education; and having been employed. The effect of the student status is in line with the idea that studying and childbearing can be hardly combined and that studying has a mechanical effect on delaying the first child. Higher and medium completed education also has a negative effect in all countries except Denmark and Germany. This result suggests that the pure mechanical effect of being a student is not the only relevant dimension in delaying fertility produced by education. It shows rather that in several countries the "career planning" and the "consumption smoothing" motives (see Gustafsson, 2001) for more educated women contribute to the delay of the first childbirth. This is also suggested by the negative effect of the attachment to the labor market -

\footnotetext{
${ }^{12}$ That is, the postponement for highly educated women that might be exactly equal to the additional time they spent in the educational system.

${ }^{13}$ We do not describe in detail the estimates of the transition to the first parity, since they do not represent the main focus of our paper. Delaying of first birth in Europe has been recently investigated by Nicoletti and Tanturri (2008).
} 
proxied by the effect of having ever been employed - and the inverse-U shaped pattern of the intensity of the attachment to the labor market proxied by potential experience. This indicates that women face a higher hazard of childbirth as they get more experience in the labor market when childbearing is less damaging to their careers and current household income is relatively higher. Finally, the effect of being married - or having been married but now divorced - go in the expected direction of increasing the hazard of giving birth to the first child.

\subsection{The effect of age at first birth on the transition to the second birth}

We now turn to the main interest of the paper, which is the effect of delaying the first birth on the transition to the second birth. Table 2 shows that the effect of delaying the first birth on the hazard of the second one varies across countries. For all Mediterranean countries (Greece, Italy, Portugal and Spain), we find a significant postponement effect, as the coefficient of the age at first birth is negative. That is, giving birth to the first child at an older age has a negative effect on the hazard of achieving a second birth. We also find a negative effect of age at first birth for Ireland and the U.K. and a positive effect for Belgium, Denmark and France, which is, however, statistically insignificant.

To distinguish between a true causal effect of age at first birth from a spurious correlation due to unobserved heterogeneity, we estimate the two transitions jointly. The coefficient estimates in specification 1 of Table $3^{14}$ suggest that, conditional on observed and unobserved heterogeneity, delaying the first birth lowers the transition to the second parity in Greece, Portugal and Spain. Once we account for unobserved heterogeneity, the

\footnotetext{
${ }^{14}$ We only report in Table 3 the main variables of interest for the transition to the second birth. The full estimates from the jointly estimated model of specification 1 for both transitions are reported in Table A2 in the Appendix.
} 
effect found for Italy in the benchmark case becomes statistically insignificant. Hence, the reduced hazard of a second childbirth in Italy does not seem to be related to maternity postponement but rather seems to reflect the choice of women of both late and low fertility. ${ }^{15}$ We also find for Denmark and France that accounting for endogeneity of age at first birth leads to a significant catch-up effect: postponing the first birth positively affects the transition to the second birth. The findings for Denmark are consistent with those in Heckman et al. (1985) for Sweden, which is another Nordic country with similar institutional characteristics.

Table 4 shows the estimates of the unobserved heterogeneity distribution and the associated probabilities. The unobserved heterogeneity allows us to split a country's population among four different individual types: 1) fast parity achievers $(\mathrm{HH})$, who are fast in achieving both parities; 2) slow parity achievers (LL), who are slow in achieving both parities; 3 ) slow 1st parity achievers ( $\mathrm{LH})$, who are relatively slow in achieving the first parity but faster in achieving the second one; and 4) slow 2nd parity achievers (HL), who are relatively fast in achieving the first parity but slower in achieving the second. These unobserved characteristics may proxy for individuals' latent choices about total fertility, i.e. their desired number of children.

Based on this interpretation, in all countries, except Italy and the U.K., most women strongly prefer two children. Indeed in Belgium, Denmark, France, Germany, Greece, Ireland, Portugal and Spain, the largest fraction of the population is composed of HH-type individuals, i.e. those who are relatively fast in achieving both parities. Among these countries, the largest fraction of fast achievers is observed for Ireland, which is also

\footnotetext{
${ }^{15}$ This is in contrast to Kohler et al. (2002), who use ordinary least squares and find statistically significant and sizable postponement effects (i.e. negative correlations between age at first birth and the TFR) for both Italy and Spain.
} 
the country with the highest TFR in our sample and with the strongest religious participation (see column 3 of Table 1). By contrast, in Italy and the U.K., the largest part of the population is represented by HL-type individuals: those who are fast in achieving the first parity but slow in achieving the second one. They might represent women who only want one child. We also observe other differences in unobserved heterogeneity by country. For instance, in France and Greece, the second largest group in the population is represented by slow achievers who might be women with weak preferences for children (e.g., those who do not want children but have them unintentionally). In other countries such as Belgium, Germany, Portugal and Spain, the second largest group is composed of HL-type individuals, i.e. women who might desire only one child.

\subsection{Explaining the cross-country variation in tempo effects}

The previous analysis has revealed significant heterogeneity across countries for the effect of age at first birth on the timing of subsequent fertility, with a significant postponement effect emerging in Southern Europe and a catch-up effect found in Denmark and France. This suggests that biological (e.g. fecundability) and technological factors (e.g. availability of assisted conception methods) are unlikely to be the main explanation of this cross-country variation, as they should affect all developed countries in a similar way. By contrast, the stigma and income effects may explain these differences across countries, since their magnitude depends on the heterogeneous institutional and cultural environments which exist in Europe (see Section 2). In order to distinguish the biological and stigma effect from the income effect, we estimate a specification in which age at first birth is interacted with the dummy for having been employed (specification 2). 
Estimates from specification 2 in Table 3 show that women who have been employed are less likely to progress to the second parity. This captures the fact that in most countries the fertility of women who are employed is lower than those who are not. The non-interacted effect of the age at first birth on the hazard of the second parity is negative in all countries showing the existence of a postponement effect, which is consistent with both the biological and the stigma effects. It is interesting to note that the magnitude of the postponement effect varies across countries. This variation can be rationalized in terms of a differential stigma effect across countries, assuming that the biological effect is the same in all countries. Indeed, the postponement effect for nonemployed women is higher in Mediterranean and Catholic countries such as Italy, Portugal, Spain, Greece and Ireland, where religious and social norms are likely to shape individual preferences about childbearing and determine a larger stigma effect for giving birth late.

The interaction term between having been employed and age at first birth is meant to capture the income effect. Table 3 shows that in all countries, except the U.K., delaying the first birth raises the likelihood of progressing to the second parity for working women. ${ }^{16}$ The magnitude of this positive income effect determines the sign of the overall effect of delaying the first birth for working women. In those countries in which the positive income effect is larger than the negative effect due to the biological and stigma effects, such as in Denmark and France, the overall effect is positive (catch-up effect). In contrast, in countries such as Greece, Portugal and Spain, where the positive income effect is small and the negative stigma effect is large, the overall effect is

\footnotetext{
${ }^{16}$ For Denmark the effect of age at first birth refers to those women who have been employed. The effect of having been employed cannot be identified due to low variation, as most of women have been employed at least once in their lifetime.
} 
negative (postponement effect).

As we have already discussed in section 2 , the relative difference in the magnitude of the income effect across countries might be explained by the difference in their labor markets and childcare institutions. The flexible working arrangements and the high provision of public childcare observed in countries such as Denmark and France, may lead to a relatively large income effect, as the opportunity cost of childbearing is lower, and women can easily combine work and childrearing. By contrast, the income effect is expected to be relatively small in Southern European countries due to the low provision of external childcare and the lack of flexibility in the labor market, which help when combining family and work.

\subsection{Simulations}

The above analysis has shown that there are statistically significant tempo effects in some European countries and that their magnitude and sign vary across countries. To gauge the magnitude of these effects on fertility, we compute the conditional probability to progress to the second birth within five years after the first birth under different scenarios with respect to the age of first birth. The first scenario is when the age at first birth is 25 , which is close to the average observed in most European countries. The second scenario is where the age at first birth increases to 30 . We distinguish between working and nonworking women, and we fix other characteristics at their mean sample values at the country level.

Table 5 reports the difference in the probability in having a second childbirth within five years of the first birth, induced by a change in the age at first birth from 25 to 
30. The effects are estimated by women's working status and by country. Here we comment only on the effects that were found to be statistically significant. It can be seen immediately that the large catch-up effects for working mothers in Denmark and France, where delaying age at motherhood by five years leads to an increase in the likelihood of having a second childbirth within the following five years by almost 20 percentage points (p.p.) and 12 p.p., respectively. Catch up effects are also observed for working women in other countries, although they are much smaller in magnitude. As for non-working women, our simulations predict large postponement effects for Greece (-12.6 p.p.) and Ireland (-10.6 p.p.), and smaller effects for Spain and Portugal (-3.5 and -2.9 p.p., respectively).

\section{Conclusion}

We investigate the effect of delayed motherhood on fertility dynamics by focusing on the causal effect of the age at first birth on the transition to the second parity for a number of European countries with different institutional environments. We show that the effect of delayed motherhood differs both across countries and among working and non-working women. The heterogeneous effects across countries - with a significant postponement effect emerging in Southern Europe and a catch-up effect found for Denmark and France - suggest that biological and technological factors are unlikely to be the main explanation of this cross-country variation, as they should similarly affect all developed countries.

To understand this cross-country variation we consider the role of stigma and income effects whose magnitude depends on the heterogeneous institutional and cultural environments that exist in Europe. We find that for non-working women, delayed 
motherhood leads to a postponement effect which is higher in the Mediterranean countries, where religious and social norms determine a relative larger stigma effect for giving birth late. For working women, delaying the first birth raises the likelihood of progressing to the second parity, presumably due to an income effect, which is larger in countries such as Denmark and France, with high childcare provision and part-time employment opportunities. By contrast, the income effect is expected to be relatively small in Southern European countries due to the low provision of external childcare and the lack of flexibility in the labor market.

We show that the overall effect of delayed motherhood depends on two opposite forces. In those countries in which the positive income effect is larger than the negative effect due to the biological and stigma effects, the overall effect is positive, and a catchup effect emerges. In contrast, in countries where the positive income effect is small and the negative stigma effect is large, the overall effect is negative, and we observe postponement effects. As to the magnitude of the tempo effects that we find on fertility, our estimates suggest that delaying the age at motherhood by five years - from 25 to 30 leads to a positive effect on the likelihood of having a second childbirth as high as 19 p.p. for countries such as Denmark, and a negative effect as low as -13 p.p. in Mediterranean countries such as Greece. 


\section{References}

Adserà, A., 2006. Marital fertility and religion in Spain, 1985 and 1999. Population Studies 60(2), 205-221.

Ahn, N., Mira, P., 2002. A note on the changing relationship between fertility and female employment rates in developed countries. Journal of Population Economics 15(4), 667-682.

Amuedo-Dorantes, C., Kimmel, J., 2005. The motherhood wage gap for women in the United States: The importance of college and fertility delay. Review of Economics of the Household 3(1), 17-48.

Apps, P., Rees, R., 2004. Fertility, taxation and family policy. Scandinavian Journal of Economics 106(4), 745-763.

Bettio, F., Villa, P., 1998. A Mediterranean perspective on the breakdown of the relationship between participation and fertility. Cambridge Journal of Economics 22(2), 137-171.

Blackburn, M. L., Bloom, D. E., Neumark, D., 1993. Fertility timing, wages and human capital. Journal of Population Economics 6(1), 1-30.

Bongaarts, J., 2001. Fertility and reproductive preferences in post-transitional societies. Population and Development Review, 27(Supplement), 260-281

Cameron, S. V., Heckman, J. J., 1998. Life cycle schooling and dynamic selection bias: Models and evidence for five cohorts of American Males. Journal of Political Economy 106(2), 262-333.

Cigno, A., Ermisch, J., 1989. A microeconomic analysis of the timing of births. European Economic Review 33(4), 737-760.

Davies, R., Pierre, G., 2005. The family gap in pay in Europe: A cross-country study. Labour Economics 12(4), 469-486.

Del Boca, D., Sauer, R. M., 2008. Life cycle employment and fertility across institutional environments. European Economic Review forthcoming.

Del Bono, E., Weber, A., Winter-Ebmer, R., 2008. Clash of career and family: Fertility decisions after job displacement. Economics working papers 2008-02, Department of Economics, Johannes Kepler University Linz, Austria.

Francesconi, M., 2002. A joint dynamic model of fertility and work of married women. Journal of Labor Economics 20(2), 336-380.

Gustafsson, S., 2001. Optimal age at motherhood. Theoretical and empirical considerations on postponement of maternity in Europe. Journal of Population Economics 14(2), 225-47.

Heckert, A., Teachman, J. D., 1985. Religious factors in the timing of second births. Journal of Marriage and the Family 47(2), 361-367.

Heckman, J. J., Hotz, V. J., Walker, J., 1985. New evidence on the timing and spacing of births. American Economic Review 75(2), 179-184.

Heckman, J., Singer, B., 1984. The identifiability of the proportional hazard model. Review of Economic Studies 51(2), 231-241. 
Hotz, V. J., Miller, R. A., 1988. An Empirical Analysis of Life Cycle Fertility and Female Labor Supply. Econometrica 56(1), 91-118.

Howe, G., Westhoff, C., Vessey, M., Yeates, D., 1985. Effects of age, cigarette smoking and other factors on fertility, findings in a large prospective study. British Medical Journal 290(6483), 1697-1700.

Kohler, H., Billari, F. C., Ortega, J. A., 2002. The emergence of lowest-low fertility in Europe during the 1990s. Population and Development Review 28(4), 641-680.

Kohler, H. P., Skytthe A., Christensen, K., 2001. The age at first birth and completed fertility reconsidered: Findings from a sample of identical twins, MPIDR Working Paper No. 2001-006, Max Planck Institute for Demographic Research, Rostock.

Lancaster. T., 1990. The Econometric Analysis of Transition Data. Cambridge University Press, Cambridge.

Lutz, W., Skirbekk, V., 2005. Policies addressing the tempo effect in low-fertility countries. Population and Development Review 31(4), 699-720.

Martínez, D. F., Iza, A., 2004. Skill premium effects on fertility and female labor force supply. Journal of Population Economics 17(1), 1-16.

Miller, A., 2008. The effects of motherhood timing on career path, mimeo, University of Virginia.

Moffitt, R., 1984. Profiles of fertility, labour supply and wages of married women: A complete life-cycle model. Review of Economic Studies 51(2), 263-78.

Morgan, S. P., Rindfuss, R. R., 1999. Reexamining the link of early childbearing to marriage and to subsequent fertility. Demography 36(1), 59-75.

Nicoletti, C., Tanturri, M. L., 2008. Differences in delaying motherhood across European countries: Empirical evidence from the ECHP. European Journal of Population, 24(2), 157-183.

van Noord-Zaadstra, B. M., Looman, C. W., Alsbach, H., Habbema, J. D., te Velde, E. R., Karbaat, J., 1991. Delaying childbearing: Effect of age on fecundity and outcome of pregnancy. British Medical Journal 302(6789), 1361-1365.

van den Berg, G. J. 2001. Duration models: specification, identification and multiple durations. In: Heckman, J. J., Leamer E. (Eds.), Handbook of Econometrics, vol V. North-Holland, Amsterdam (Chapter 55).

van Ours, J. C. 2003. Is Cannabis a stepping-stone for cocaine? Journal of Health Economics 22(4), 539-554.

van Ours, J. C. 2004. A pint a day raises a man's pay; but smoking blows that gain away. Journal of Health Economics 23(5), 863-886.

Walker, J. R., 1995. The effect of public policies on recent Swedish fertility behavior. Journal of Population Economics 8(3), 223-251. 


\begin{tabular}{|c|c|c|c|c|c|c|c|c|c|}
\hline & & 1) & (2) & (3) & (4) & (5) & (6) & (7) & (8) \\
\hline & \multicolumn{2}{|c|}{ Child-Care Coverage $^{\mathrm{a}}$} & Part-Time $^{c}$ & $\begin{array}{c}\text { Religious } \\
\text { participation }\end{array}$ & Sample Size $^{\mathrm{d}}$ & Has Worked $^{\mathrm{d}}$ & Share of & Share of Women with & Mean Age \\
\hline & \multicolumn{2}{|c|}{$\%$} & $\%$ & $\%$ & & $\%$ & Childless Women ${ }^{\text {de }}$ & more than 1 Child $^{\mathrm{de}}$ & at First Birth ${ }^{\text {de }}$ \\
\hline & 0-3 Years old & 3-6 Years old & & & & & $\%$ & $\%$ & \\
\hline Belgium & 30 & 97 & 36.9 & - & 718 & 94.84 & 14.01 & 52.47 & 26.07 \\
\hline Denmark & 64 & 91 & 34.7 & 6.7 & 537 & 98.88 & 14.35 & 46.03 & 26.87 \\
\hline France & 29 & 99 & 31.4 & 13.4 & 810 & 92.83 & 13.55 & 57.01 & 25.17 \\
\hline Germany & 10 & 78 & 37.2 & 17.1 & 737 & 75.84 & 18.54 & 38.54 & 25.21 \\
\hline Greece & 3 & 46 & 10.0 & - & 1232 & 76.94 & 13.10 & 63.16 & 24.07 \\
\hline Ireland & 38 & 56 & 30.1 & 73.3 & 880 & 95.79 & 13.76 & 63.84 & 25.89 \\
\hline Italy & 6 & 95 & 15.6 & 43.6 & 1801 & 72.62 & 20.30 & 40.97 & 26.16 \\
\hline Portugal & 12 & 75 & 16.7 & 40.6 & 1018 & 84.57 & 14.63 & 48.97 & 23.86 \\
\hline Spain & 5 & 84 & 17.1 & 36.2 & 1689 & 87.98 & 18.10 & 46.66 & 25.79 \\
\hline UK & $34^{\mathrm{b}}$ & $60^{b}$ & 44.0 & 16.9 & 898 & 95.87 & 17.54 & 49.60 & 26.25 \\
\hline
\end{tabular}

Source: a) Employment Outlook 2001. The data for coverage refer to the proportion of young children using formal child-care arrangements which include both public and private provision. b) England only. c) Eurostat 1999. d) ECHP(1994-2001). e) for women aged 35+ at the last observed wave. 


\section{Duration to First Birth}

Student

High Education

Medium Education

Married

Divorced

Has Been Employed

Years since First Job

Years since First Job^2

Constant

\section{Duration to Second Birth}

Age at First Birth

High Education

Medium Education

Married

Divorced

Has Been Employed

Years since First Job

Years since First Job^2

First Child a Boy

Constant

Log-Likelihood/N

\begin{tabular}{|c|c|c|c|c|c|c|c|c|c|}
\hline \multicolumn{2}{|c|}{ Belgium } & \multicolumn{2}{|c|}{ Denmark } & \multicolumn{2}{|c|}{ France } & \multicolumn{2}{|c|}{ Germany } & \multicolumn{2}{|c|}{ Greece } \\
\hline Coef. & s.e. & Coef. & s.e. & Coef. & s.e. & Coef. & s.e. & Coef. & s.e. \\
\hline-0.790 & 0.25 & -0.576 & 0.18 & -1.484 & 0.433 & -0.786 & 0.181 & -0.506 & 0.217 \\
\hline-0.151 & 0.1 & 0.149 & 0.28 & -0.377 & 0.1 & 0.668 & & -0.352 & 0.113 \\
\hline-0.088 & 0.123 & 0.450 & 0.282 & -0.353 & 0.103 & 0.331 & 0.132 & -0.345 & 0.100 \\
\hline 2.000 & 0.109 & 1.542 & 0.119 & 1.960 & 0.094 & 2.236 & 0.105 & 4.181 & 0.138 \\
\hline 0.799 & 0.132 & 0.285 & 0.15 & 1.142 & 0.138 & 0.632 & 0.133 & 1.788 & 0.197 \\
\hline-1.513 & 0.254 & & & -1.381 & 0.231 & 0.036 & 0.169 & -0.062 & $0.11 \mathrm{C}$ \\
\hline 2.131 & 0.449 & 2.025 & 0.460 & 2.573 & 0.449 & 1.146 & 0.3 & 0.637 & 0.263 \\
\hline-1.312 & 0.258 & -1.021 & 0.243 & -1.492 & 0.246 & -0.505 & 0.22 & -0.338 & 0.160 \\
\hline-2.186 & 0.289 & -3.385 & 0.397 & -2.024 & 0.247 & -3.794 & 0.221 & -5.055 & 0.213 \\
\hline 0.016 & 0.024 & 0.021 & 0.027 & 0.028 & 0.024 & -0.008 & 0.0 & -0.051 & 0.014 \\
\hline 0.380 & 0.163 & 1.139 & 0.441 & 0.115 & 0.16 & -0.108 & $0.1^{7}$ & -0.422 & 0.120 \\
\hline 0.135 & 0.146 & 1.141 & 0.438 & -0.021 & 0.11 & -0.066 & & -0.178 & 0.10 \\
\hline 0.302 & 0.167 & 0.554 & 0.139 & 0.663 & 0.123 & 0.637 & 0.18 & 1.045 & 0.261 \\
\hline-0.262 & 0.189 & -0.059 & 0.195 & 0.022 & 0.172 & -0.166 & 0.1 & -0.367 & 0.251 \\
\hline-0.192 & 0.333 & & & -0.744 & 0.352 & 0.354 & 0.25 & 0.301 & 0.147 \\
\hline 0.570 & 0.446 & 1.395 & 0.607 & 0.884 & 0.478 & 0.284 & 0.418 & -0.238 & 0.251 \\
\hline-0.529 & 0.201 & -0.631 & 0.232 & -0.627 & 0.19 & -0.208 & 0.2 & 0.067 & 0.130 \\
\hline-0.016 & 0.110 & -0.043 & 0.13 & -0.018 & 0.10 & 0.170 & 0.120 & -0.020 & 0.08 \\
\hline-2.409 & 0.605 & -4.242 & 0.761 & -1.802 & 0.535 & -2.060 & 0.570 & -1.074 & 0.417 \\
\hline-211 & 1.42 & $-21\}$ & & -204 & & -205 & & & .73 \\
\hline
\end{tabular}

(continues) 


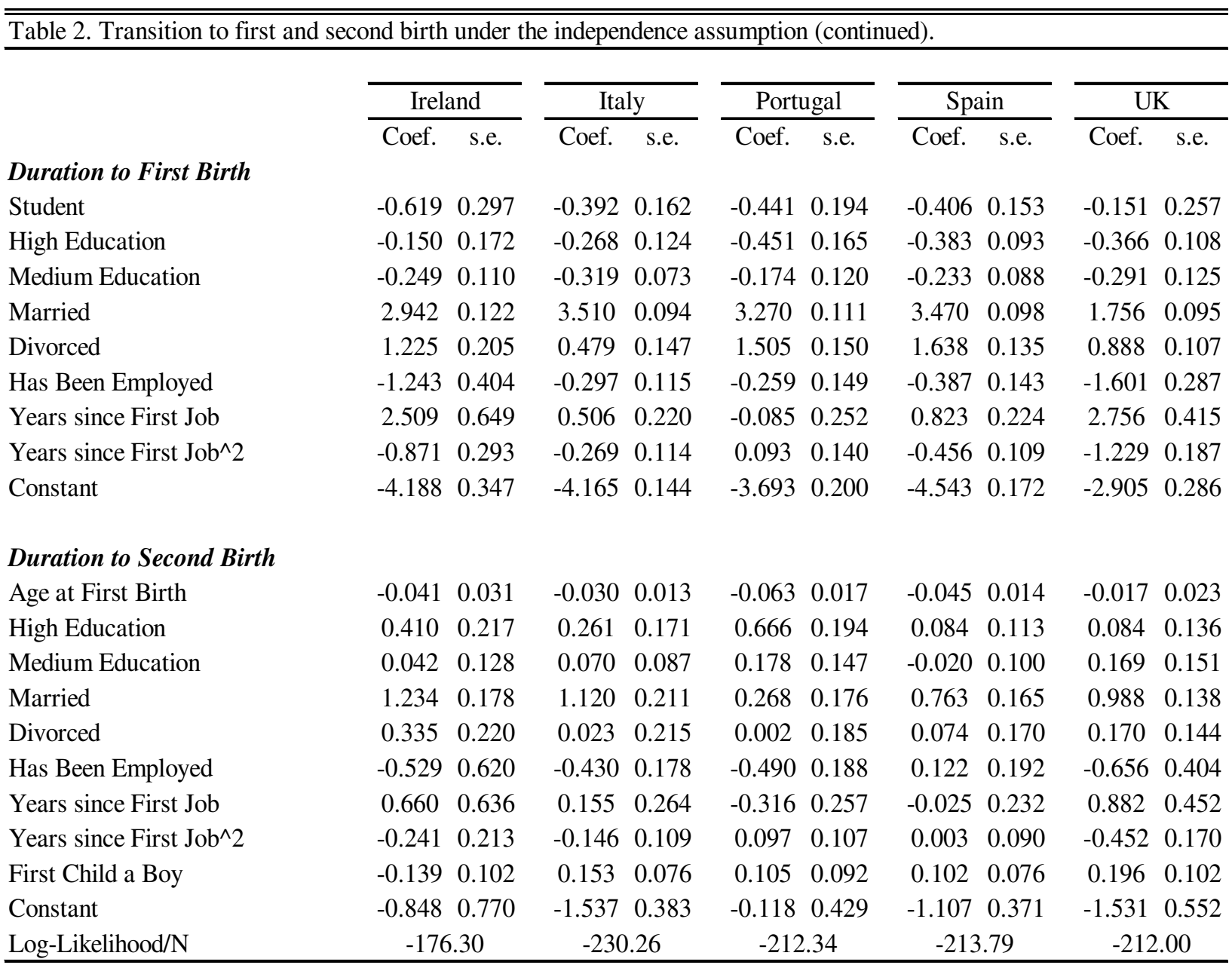

Note: The model is estimated assuming that there is no unobserved heterogeneity. Other controls include year dummies to capture time-varying policies or macro-economics factors and duration dependence dummies. For Denmark, the variable has been employed is not identified due to low variation as most of women have been employed at least once in their lifetime. 
Table 3. The effect of age at first birth on the duration to second birth.

\section{Specification 1}

Has Been Employed

Log-Likelihood/N

Specification 2

Age at First Birth

Age at First Birth*Has Been Employed

Ever Being Employed

Log-Likelihood/N

\section{Specification 1}

Age at First Birth

Has Been Employed

Log-Likelihood/N

\section{Specification 2}

Age at First Birth*Has Been Employed

Ever Being Employed
Age at First Birth

Age at First Birth

Log-Likelihood/N

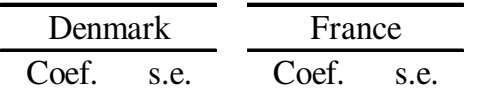

$\overline{\frac{\text { Germany }}{\text { Coef. s.e. }}}$

$\frac{\text { Greece }}{\text { Coef. s.e. }}$

Coef. s.e.

$\begin{array}{ll}0.048 & 0.039 \\ 0.135 & 0.421 \\ -211.32\end{array}$

$0.133 \quad 0.040$

$0.057 \quad 0.030$

$-0.957 \quad 0.395$

$-218.31$

$-204.52$

$\begin{array}{ll}0.006 & 0.027\end{array}$

$\begin{array}{ll}0.508 & 0.309\end{array}$

$\begin{array}{ll}-0.037 & 0.018\end{array}$

$\begin{array}{lll}0.309 & 0.390 & 0.163\end{array}$

$-205.30$

$-173.70$

\begin{tabular}{|c|c|c|c|c|c|c|c|c|}
\hline 0.058 & 0.115 & & & -0.061 & 0.067 & 0.003 & 0.039 & $\begin{array}{ll}-0.081 & 0.020\end{array}$ \\
\hline-0.010 & 0.116 & 0.133 & 0.040 & 0.137 & 0.072 & 0.004 & 0.050 & $\begin{array}{ll}0.066 & 0.019\end{array}$ \\
\hline 0.360 & 2.545 & \multicolumn{2}{|c|}{-} & -3.792 & 1.536 & 0.416 & 1.151 & $\begin{array}{ll}-0.981 & 0.402\end{array}$ \\
\hline \multicolumn{2}{|c|}{-211.39} & -21 & & \multicolumn{2}{|c|}{-204.52} & \multicolumn{2}{|c|}{-205.30} & -171.71 \\
\hline \multicolumn{2}{|c|}{ Ireland } & \multicolumn{2}{|c|}{ Italy } & \multicolumn{2}{|c|}{ Portugal } & \multicolumn{2}{|c|}{ Spain } & UK \\
\hline Coef. & s.e. & Coef. & s.e. & Coef. & s.e. & Coef. & s.e. & $\begin{array}{ll}\text { Coef. } & \text { s.e. }\end{array}$ \\
\hline-0.039 & 0.034 & -0.021 & 0.017 & -0.043 & 0.022 & -0.046 & 0.017 & $\begin{array}{ll}-0.016 & 0.025\end{array}$ \\
\hline-0.545 & 0.664 & -0.592 & 0.227 & -0.844 & 0.222 & 0.103 & 0.228 & $-0.693 \quad 0.446$ \\
\hline \multicolumn{2}{|c|}{-176.28} & \multicolumn{2}{|c|}{-230.24} & \multicolumn{2}{|c|}{-212.29} & \multicolumn{2}{|c|}{-213.76} & -211.98 \\
\hline
\end{tabular}

$\begin{array}{llllll}-0.195 & 0.053 & -0.116 & 0.080 & -0.085 & 0.048 \\ 0.225 & 0.061 & 0.110 & 0.084 & 0.045 & 0.050\end{array}$

$\begin{array}{ll}-0.134 & 0.046\end{array}$

$0.101 \quad 0.051$

0.0850 .086

$0.225 \quad 0.061$

$0.110 \quad 0.084$

$0.045 \quad 0.050$

$-2.3351 .184$

$-0.1070 .087$

$\begin{array}{lll}-176.28 & -248.98 & -212.33\end{array}$

$-213.21$

1.929

: Specification 2 allows for an interaction of age at first birth with ever been employed. Each model is estimated allowing for correlated unobserved heterogeneity. Table A2 reports the coefficient estimates for other controls for specification 1. We also include year dummies to capture time-varying policies or macro-economics factors and duration dependence dummies. For Denmark, the effect of age at first birth refers to those women who have been employed. The variable has been employed is not identified due to low variation as most of women have been employed at least once in their life-time. 


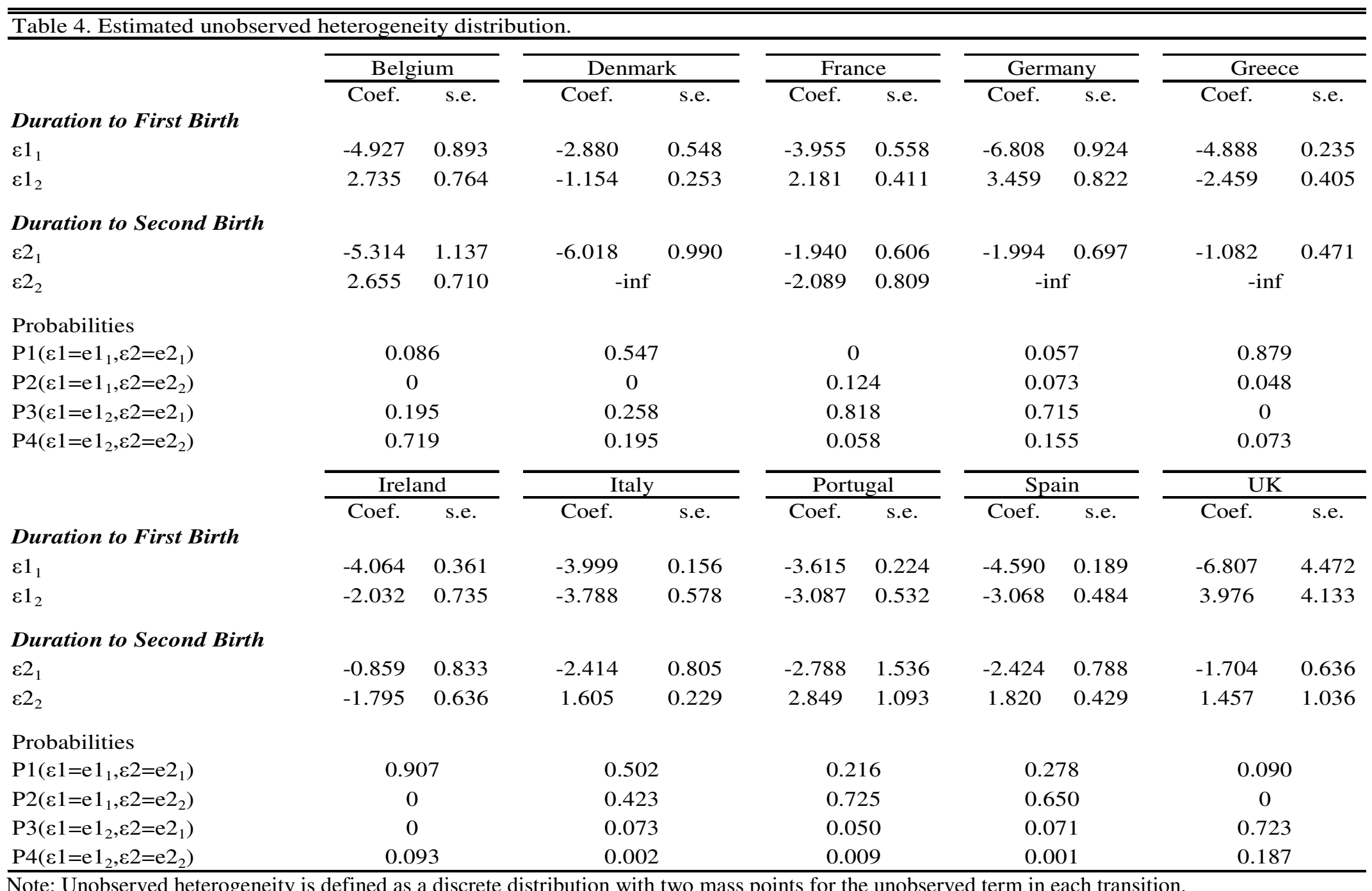




\begin{tabular}{|c|c|c|}
\hline & Non-Working & Working \\
\hline Denmark & - & 0,192 \\
\hline Belgium & 0,031 & 0,021 \\
\hline France & $-0,089$ & 0,119 \\
\hline Germany & 0,005 & 0,012 \\
\hline Greece & $-0,126$ & $-0,022$ \\
\hline Ireland & $-0,106$ & 0,024 \\
\hline Italy & $-0,036$ & $-0,002$ \\
\hline Portugal & $-0,029$ & $-0,006$ \\
\hline Spain & $-0,035$ & $-0,012$ \\
\hline UK & 0,096 & $-0,034$ \\
\hline
\end{tabular}

Note: This table shows the change in the predicted probability of having the second child within 5 years of the first one induced by an increase in the age at motherhood from 25 to 30. Positive differences represent catch up effects and negative ones postponement effects. The effect on fertility is computed at country specific sample mean values for the other regressors. 


\begin{tabular}{|c|c|c|c|c|c|c|c|c|c|c|}
\hline & Belgium & Denmark & France & Germany & Greece & Ireland & Italy & Portugal & Spain & UK \\
\hline Age & 32.29 & 32.31 & 32.56 & 30.83 & 32.41 & 32.49 & 32.17 & 32.35 & 32.18 & 32.08 \\
\hline Married & 0.70 & 0.49 & 0.59 & 0.66 & 0.81 & 0.75 & 0.77 & 0.79 & 0.74 & 0.61 \\
\hline Number of Children & 1.42 & 1.23 & 1.58 & 1.08 & 1.40 & 1.71 & 1.05 & 1.40 & 1.13 & 1.33 \\
\hline High Education & 0.43 & 0.52 & 0.24 & 0.36 & 0.32 & 0.16 & 0.12 & 0.10 & 0.30 & 0.36 \\
\hline Mean Duration to 1st Birth & 11.64 & 12.36 & 10.96 & 11.68 & 10.41 & 11.61 & 12.74 & 10.13 & 12.17 & 12.44 \\
\hline Mean Duration to 2nd Birth & 6.05 & 5.94 & 6.26 & 6.50 & 5.47 & 4.59 & 6.56 & 7.65 & 6.49 & 5.49 \\
\hline Number of Observations & 718 & 537 & 810 & 737 & 1232 & 880 & 1801 & 1018 & 1689 & 898 \\
\hline
\end{tabular}




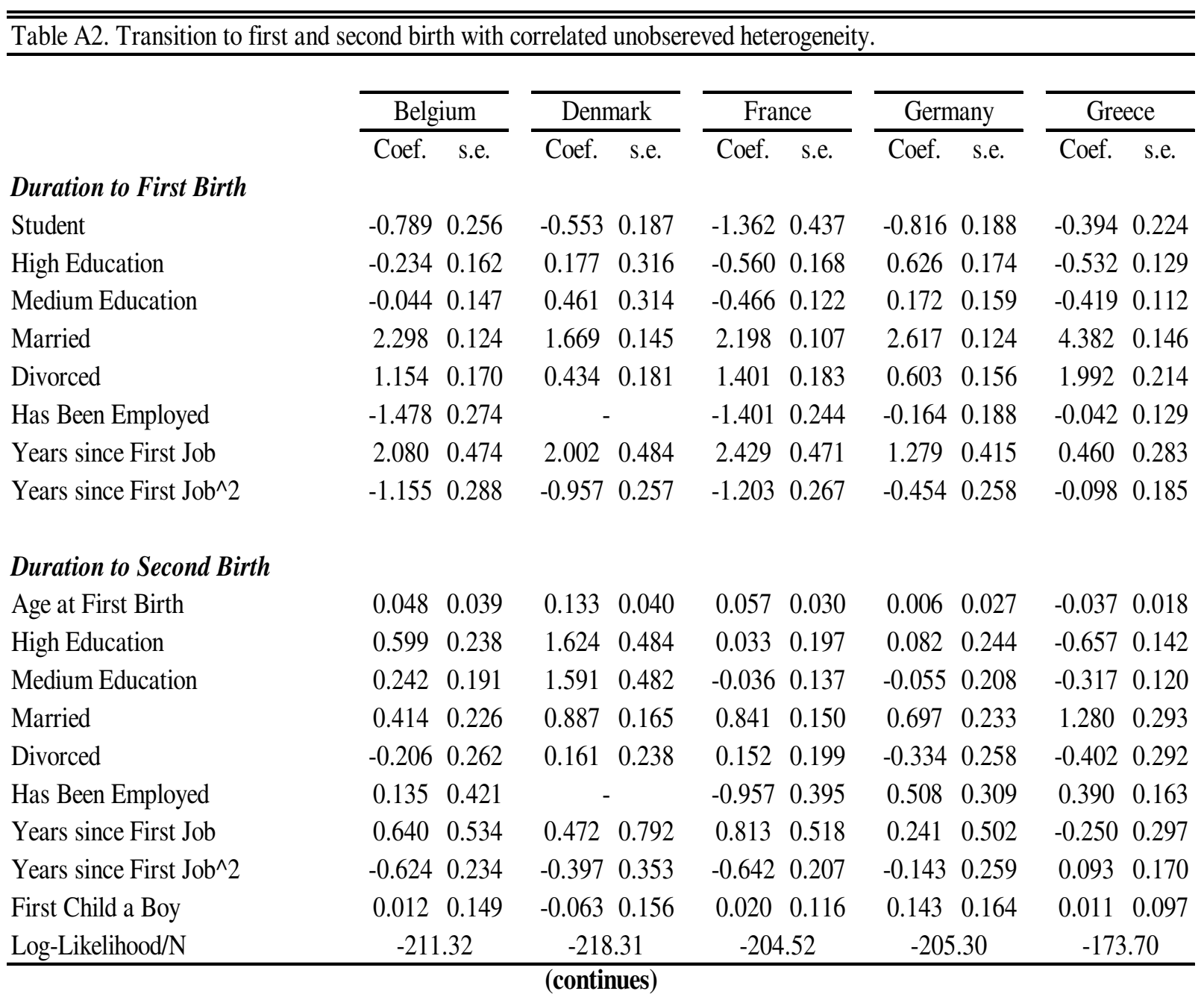




\begin{tabular}{|c|c|c|c|c|c|c|c|c|c|c|}
\hline & Irela & & Ita & & Port & ugal & $\mathrm{Sp}_{\mathrm{i}}$ & & $\mathrm{Ul}$ & \\
\hline & Coef. & s.e. & Coef. & s.e. & Coef. & s.e. & Coef. & s.e. & Coef. & s.e. \\
\hline \multicolumn{11}{|l|}{ Duration to First Birth } \\
\hline Student & -0.585 & 0.304 & -0.333 & 0.167 & -0.349 & 0.205 & -0.403 & 0.159 & -0.085 & 0.262 \\
\hline High Education & -0.344 & 0.190 & -0.560 & 0.141 & -0.703 & 0.183 & -0.518 & 0.104 & -0.335 & 0.132 \\
\hline Medium Education & -0.380 & 0.126 & -0.474 & 0.083 & -0.415 & 0.133 & -0.233 & 0.097 & -0.256 & 0.147 \\
\hline Married & 3.088 & 0.130 & 3.739 & 0.101 & 3.561 & 0.122 & 3.729 & 0.112 & 1.978 & 0.116 \\
\hline Divorced & 1.716 & 0.286 & 1.417 & 0.198 & 1.929 & 0.185 & 2.153 & 0.179 & 1.085 & 0.161 \\
\hline Has Been Employed & -1.124 & 0.429 & -0.267 & 0.123 & -0.255 & 0.159 & -0.381 & 0.154 & -1.682 & 0.387 \\
\hline Years since First Job & 2.136 & 0.689 & 0.252 & 0.253 & -0.282 & 0.266 & 0.657 & 0.263 & 2.640 & 0.450 \\
\hline Years since First Job^2 & -0.625 & 0.319 & -0.142 & 0.144 & 0.283 & 0.150 & -0.327 & 0.146 & -1.098 & 0.213 \\
\hline \multicolumn{11}{|l|}{ Duration to Second Birth } \\
\hline Age at First Birth & -0.039 & 0.034 & -0.021 & 0.017 & -0.043 & 0.022 & -0.046 & 0.017 & -0.016 & 0.025 \\
\hline High Education & 0.381 & 0.239 & 0.258 & 0.217 & 0.670 & 0.280 & 0.141 & 0.144 & 0.102 & 0.151 \\
\hline Medium Education & -0.018 & 0.152 & 0.081 & 0.111 & 0.073 & 0.194 & 0.030 & 0.127 & 0.179 & 0.170 \\
\hline Married & 1.403 & 0.237 & 1.371 & 0.255 & 0.601 & 0.235 & 1.033 & 0.205 & 1.085 & 0.168 \\
\hline Divorced & 0.568 & 0.280 & 0.145 & 0.271 & 0.333 & 0.276 & 0.199 & 0.219 & 0.184 & 0.163 \\
\hline Has Been Employed & -0.545 & 0.664 & -0.592 & 0.227 & -0.844 & 0.222 & 0.103 & 0.228 & -0.693 & 0.446 \\
\hline Years since First Job & 0.596 & 0.681 & 0.321 & 0.328 & -0.114 & 0.306 & -0.044 & 0.275 & 0.931 & 0.498 \\
\hline Years since First Job^2 & -0.176 & 0.234 & -0.229 & 0.136 & -0.034 & 0.142 & 0.024 & 0.111 & -0.476 & 0.186 \\
\hline First Child a Boy & -0.118 & 0.110 & 0.210 & 0.097 & 0.158 & 0.119 & 0.141 & 0.097 & 0.211 & 0.113 \\
\hline Log-Likelihood/N & -176 & & -230 & & -212 & 2.29 & -213 & & -211 & \\
\hline
\end{tabular}

